\title{
Introduction: the changing nature of economics - towards an ecological economics
}

\author{
Cutler J. Cleveland, Robert Costanza and \\ David I. Stern
}

Like any field of scientific inquiry, ecological economics has evolved along several different fronts. One important element is an understanding of the history of the field, which is characterized by interwoven strands from ecology, physics, the physiocratic and classical schools of economics, and other fields in the social and natural social sciences. Another important area is the relation of neoclassical economics to ecological economics. Part of the impetus behind the creation of the International Society for Ecological Economics was the growing recognition that, by itself, neoclassical economics could not fully explain the sources of depletion and degradation, nor could it provide a reliable compass for future development. A third broad strand of work is the empirical analysis of energy and material flows within and between economic and environmental systems. This work ranges widely, from the construction of sustainability indicators to land use models.

This book covers some of the important recent developments in the theory, concepts and empirical applications of ecological economics and sustainable development. It contains contributions from some of the leading scholars in the field of ecological economics. The book is divided into two parts. Part I, The Nature of Economics, includes chapters on the contribution of classical economics to ecological economics, valuation in ecological economics, the role of communication in the discourse on sustainable development, and a classification system for theories and methods in ecological economics. Part II, The Economics of Nature, includes chapters on alternatives to the growth paradigm, case studies of sustainable development and critical reviews of the environmental Kuznets curve, green national accounting, indicators of natural resource scarcity, and alternatives to gross domestic product. 


\section{THE NATURE OF ECONOMICS}

The history of the evolution of ecological economics provides insight into the current state of the field. Part of this history is the continuing tension between the neoclassical approach and alternative economic paradigms within ecological economics. In his chapter, Paul Christensen points out that the relationship between ecological economics and neoclassical economic theory continues to be problematic. Many ecological economists argue that standard market theory, when corrected for externalities or extended to include environmental accounting, provides a satisfactory framework for analysing economic processes and environmental problems.

Christensen argues that the mechanistic individualism of modern (neoclassical) economic theory is inconsistent with the materials, energetic and organismic interdependence that structures ecological systems. Most working economists admit that the assumptions of neoclassical theory are excessively abstract and unrealistic and argue that the theory has to be extended. But what is not sufficiently understood is that this extension cannot take place without a fundamental recasting of basic assumptions.

Christensen traces the very different way in which physiocratic and classical economics evolved relative to the later neoclassical theory. The former emerged as part of the early evolution of the natural sciences, moral philosophy and a naturalistic psychology. Early economic theories of production were developed from contemporary ideas of active matter employed in chemical and physiological theories of the way nature reproduced itself through time. The result is a body of theory that provides a framework for an explicit account of the interdependence between materials and energy and the technologies of material and energy conversion. It is a framework, moreover, that is connected to psychological models concerned with the interdependence between emotion and reason and with learning through time.

Neoclassical theory, by contrast, took its concepts and mathematical structure from the maximization framework of analytical mechanics and field theory. The result is a treatment of economic agents as charged particles at equilibrium in a field of forces. Precisely because it is structured by the field model of a conserved gradient of potential energy, the neoclassical model of production (and utility) lacks a physically realistic treatment of materials and energy or the technologies by which materials, energy and information are transformed in economic activity.

Christensen describes the steps in the development of an ecological approach to economics. The first is a scientifically informed characterization of production inputs and processes. This would be based on an ecological characterization of flows of materials, energy and information, and the technologies, organization and learned skills that transform and convert materials, energy 
and information. A second and related step is an accurate representation of the distinct differences, constraints and productive potential of the biological and ecologically based 'sectors' of nature's economy versus the technologically constructed sectors of human industrial activity which are currently dependent on the entropic use of vast supplies of inorganic minerals and fossil fuels.

Joan Martinez-Alier and his colleagues provide a useful classification of concepts, theories and methods in ecological economics. The classification is made according to the criterion of comparability of values, emphasizing weak comparability as the foundation of ecological economics. The economy is embedded not only in the social perception of energy and material flows (which is historically changing), but is also in social institutions, such as the distribution of property rights, the distribution of power and the distribution of income. While conventional environmental and resource economics rests on principles of compensation and substitution, which sometimes might be operative, ecological economics emphasizes the difficulties in substituting for the loss of environmental goods such as biodiversity (which is not even inventoried), or in compensating future generations for the uncertain, irreversible negative externalities we cause today. As a consequence, theories and methods such as reflexive complexity, biophysical indicators and non-compensatory multicriteria evaluation become useful.

Martinez-Alier et al. note that ecological economists understand and sometimes share the conventional economists' attempts to 'internalize' externalities into the price system. But they emphasize the uncertainties and complexities which make it difficult to obtain physical measures of external impacts, let alone economic measures of externalities. Attempts at internalization are likely to be successful in some specific cases only. Instead, ecological economists often sympathize with the less ambitious 'costeffectiveness' approach where standards are devised by methods from outside conventional economics but conventional economic instruments may be used to realize those standards. Martinez-Alier et al. emphasize how economic values depend on the intergenerational and intragenerational inequalities in the distribution of the burdens of pollution and in the access to natural resources. They argue that ecological economics must explicitly refuse the complete commensurability paradigm and recognize the existence of incommensurability of values. This is mainly because the environment is a site of conflict among competing values and interests and among different groups and communities that hold them.

Martinez-Alier et al. conclude that policy recommendations should be defensible to the technical expert, but also to politicians, the media and the various stakeholders. This does not imply that a consensus will be reached. Indeed, the possibility of irreconcilable differences is recognized and allowed for by promoting a plurality of approaches. Since multicriteria evaluation 
techniques are based on a 'constructive' rationality and allow one to take into account conflictual, multidimensional, incommensurable and uncertain effects of decisions, they appear to be a promising assessment framework for (micro and macro) environmental policy. Multicriteria evaluation techniques cannot solve all conflicts, but they can help to provide more insight into the nature of conflicts and into ways to arrive at political compromises in case of divergent preferences, thereby increasing the transparency of the choice process.

In Chapter 3, Richard Norgaard emphasizes the importance of understanding and communication to achieving sustainability. While ecology and economics share many conceptual roots, the modern orchestration between the disciplines proved dysfunctional, the cacophony ringing out in raucous political debate, during the second half of the twentieth century. Norgaard identifies some clear differences between the now fading modern orchestration and the emerging improvisation. First, ecological economists are actively engaged in encouraging a paradigm shift. We are very aware that modern Western and Westernized societies have been constructed around fundamental beliefs in material progress driven by science dedicated to controlling a malleable natural system without resource limits. We believe that these beliefs are not only fundamentally in error but also the cause of environmental as well as social problems. Ecological economics exists in part to actively challenge scientists and policy makers to make the necessary changes in their thinking on these matters.

Second, the 'social scientists' among ecological economists are keenly interested in biophysical measures of human resource use. Third, ecological economics pays as much attention to scale and equity as to efficiency. A fair system of access to resources is critically important to the way people interact with the environment. As important as the mechanics of the market can be, we do not stress efficiency alone. We know that prices are not only a function of whether the market is working efficiently but also a matter of how rights to resources are distributed among people within nations, between nations and over generations.

Fourth, ecological economists realize that understanding problems and finding and implementing solutions requires the contextual, experiential and, in some cases, traditional or indigenous knowledge of local people and practitioners. Accuracy to two significant figures in the aggregate does not imply that good solutions will be achieved across a diversity of ecological, technological, social and cultural contexts. Participatory research conducted in a partnership between scientists and those who will actually implement a solution is frequently the only way to reach workable answers and effective solutions. Finally, ecological economists are historically and philosophically conscious of the interplay between assumptions, models and the types of answers they can generate. We know that the viability of answers depends on the broader social structure in which such answers may be effective. We are wary of the ideology supporting existing approaches to economic research, with their feigned objectivity. We 
are concerned that these approaches were largely designed to replace democratic decision making and the broad empowerment that makes implementation of solutions possible. We do not have workable solutions within the historic orchestration and in the transition to new improvisations we find ourselves in awkward contradictions. We are open to what we do not know, aware that learning more also entails learning more about what we do not know, and find adaptive environmental management a suitable approach for these reasons.

According to Daniel Bromley, sustainability is at once a fine idea and a hopeless concept. It is good because it reminds us of the fate of future persons; it is hopeless because it begs for operational content. The better part of wisdom suggests that we should take it on its own terms - but not ask too much of it. As a metaphor to guide action, it is probably quite adequate. But we must move to another epistemological programme to ascertain what we should do about the future. That alternative programme is not the Smithian machine and its providential spontaneous order. It is, instead, the Kantian imperative of Pure Reason applied to future persons. From this comes the demand for a constructed order that will ensure particular settings and circumstances for future persons.

Bromley observes that traditional approaches to sustainability rely on models that depend upon judgments of welfare across future generations, 'right prices' and some sense as to what future persons will find giving of utility. These models both accept the spontaneous order of market processes and rely on that order to derive optimal consumption paths into the future. However, sustainability is not a problem of divining optimal paths predicated upon right prices. Rather, sustainability, to be operational, requires the idea of a constructed order predicated upon rights for future persons. It also implies duties for those now living who sit in a position of dictator over the settings and circumstances that will be passed on to future persons. Rights-based approaches to sustainability do not rely upon unknowable preferences of future persons, but rather upon an environmental regency in which those now living agree to preserve settings and circumstances for the future. This reminds us that the central issue in sustainability concerns not how much to preserve but rather what to preserve.

The issue of valuation is central to economics. Its pursuit has been cast in questions of what constitutes value, how value is created and how value is expressed in economic activity and economic institutions. In Chapter 5, Sabine O'Hara shows that, while the interest in value and value creation is equally pertinent to ecological economics, ecological economists have framed valuation questions differently from their mainstream colleagues. Ecological economists generally view with scepticism the reliance on prices as the primary expression of value. The reason for this is that ecological economics has added considerable complexity to the model of market exchange advanced in mainline economics. Ecological economics views economic activity as taking place within a larger context of material flows which originate in the environment, 
are processed in economic activity and released back into the environment as high entropy waste. Further complexity is added by those who contend that material flows are not simply an expression of 'natural processes' linking human economic activity to its biophysical context, but reflect the social and cultural context of human activity as well

O'Hara calls for a methodology that allows the complexities of all systems to be explicitly admitted to the valuation process, rather than being implicitly considered in 'corrected' market prices. One such method is the open and uncoerced discourse of individuals in a process of mutual acceptance and respect. Such discourse can be viewed as a decentralized coordination mechanism, which gives expression to the life world with all its material constraints, social relationships and valuation patterns. For ecological economics such discourse-based valuation is of particular importance for two reasons: (1) discourse can link all systems levels and thus provides the basis for expanding familiar disciplinary valuation methods to an expressly multidisciplinary process; (2) discourse invites participation from affected stakeholders and thus questions the institutionalized segregation of 'expert' judges and 'non-expert' victims.

\section{THE ECONOMICS OF NATURE}

The second part of the book turns to more specific analyses of the economics of energy, natural resources and the environment. Robert Ayres' chapter provokes questions such as whether the need for a new paradigm means that an old one must be discarded. What does 'growth paradigm' mean? Is the chapter about the end of growth? Is it about 'limits to growth' in the sense of the 1970s debate? Or is it, perhaps, about the nature of a hypothetical 'no growth' or 'steady state' society, and some of the implications of such a society? The answer to all of these questions is no. Rather than writing just another neoMalthusian anti-growth tract, Ayres argues that economic growth is both possible and essential for social and political reasons. But the economic growth engine, as it operates today, is running amok. Economic growth in most of the world is so inequitable that by far the largest share of the benefits is being appropriated by a tiny group of those who were already rich or well connected. The so-called 'Asian Miracle' was touted as growth with equity, but its collapse has revealed a very different reality. Worse, globalization led by the multinational corporations leaves an increasing part of the population - and most of the population in many parts of the world - with little prospect of benefit, either now or in the foreseeable future. Growth as measured by gross domestic product (GDP), even where it is more than keeping up with population, is not producing comparable increases in real social welfare. In short, the present pattern of growth is socially unsustainable. 
Ayres argues that the present pattern of economic growth, which is based on increasing labour productivity by substituting physical capital based on fossil resources for human workers, is also ecologically and environmentally unsustainable. The most binding limits are of so-called renewable and environmental resources. The two most immediate problems are water and wood. A third, and arguably more serious, problem is that the toxic waste assimilative capacity of the earth is declining - as a consequence of the degradation and loss of topsoil, deforestation and loss of biodiversity - while the demand for this service of nature is rising. A fourth problem, much more widely known, albeit still difficult to evaluate quantitatively, is climate change and its associated dangers.

Ayres points out that economic growth in the future must provide the resources to compensate for these problems, while not being short-circuited by them. Clearly, it must be technology driven. But the technologies that are needed will have to substitute solar energy and non-material resources - especially information - for material resources. Of course, the ultimate resource is trained human intelligence, which is the main source of our hopes for long-term survival as a species. Unfortunately, politicians in all the countries of the West, but especially in continental Europe, have unwittingly compromised this one essential resource. They have sharply limited the possibility of investment in the needed education and scientific research by committing future 'growth dividends' to current consumption by and subsidies to all sorts of politically well connected groups. The research and development (R\&D) and investment deficit is slowing growth when and where it is most needed. A day of reckoning is fast approaching.

Mohan Munasinghe sets out a practical framework to better integrate economic, social and environmental components of sustainability based on ecological economics. The approach seeks to make development more sustainable by eliminating unsustainable activities, which is more practical than to define the ideal state of sustainable development. The use of this framework is described at various hierarchic levels of decision making - project/local, sectoral/subnational, economywide/national and global/transnational. Concepts and techniques for valuation of environmental impacts of projects and policies are presented that enable such environmental considerations to be explicitly considered in the conventional cost-benefit calculus used in economic decision making. The process of internalizing these environmental externalities may be facilitated by extending the techniques of conventional economic theory, with particular reliance on willingness-to-pay as a measure of value. Problems caused by discounting, risk and uncertainty are discussed. When economic valuation of environmental impacts is difficult, reliance may have to be placed on multicriteria methods. Economywide policies (both sectoral and macroeconomic) often have significant environmental effects. The solution is not necessarily to modify the original broader policies (which have conventional economic or 
poverty-related goals), but rather to design more specific and complementary environmental measures that would address the particular policy, market or institutional imperfection and thereby help mitigate negative effects or enhance positive impacts of the original policies on the environment.

Munasinghe presents a series of case studies that span the hierarchic levels of decision making: rainforest management in Madagascar, improving energy sector decision making in Sri Lanka, and several case studies of the environmental and social impacts of countrywide policies such as structural adjustment programmes. Overall, the case studies suggest that economic techniques exist - and, for most countries, so does natural resource information - to improve the way environmental issues are addressed at the project, sector and macro levels. While significant data problems remain, the studies illustrate the feasibility of making rough assessments, not simply of environmental impacts of projects, but also of economic policies (and in particular economywide policies), thereby hastening the integration of the environment into the mainstream of economic decision making.

David Stern reviews the theory and applications of the environmental Kuznets curve (EKC), a hypothesis that proposes an inverted U-shape relation between various indicators of environmental degradation and income per capita. This has been taken to imply that economic growth will eventually redress the environmental impacts of the early stages of economic development and that growth will lead to further environmental improvements in the developed countries. Far from being a threat to the environment in the long term, as argued in The Limits to Growth (1972) Universe Books, New York, and Beyond the Limits (1992) Earthscan, London, among others, economic growth is seen as necessary in order for environmental quality to be maintained or improved. This is an essential part of the sustainable development argument as put forward in Our Common Future (1987), Oxford University Press.

Proponents of the EKC hypothesis argue that, at very low levels of economic activity, environmental impacts are generally low but as development proceeds the rates of land clearance, resource use and waste generation per capita increase rapidly. However, at higher levels of development, structural change towards information-intensive industries and services, coupled with increased environmental awareness, enforcement of environmental regulations, better technology and higher environmental expenditures, result in levelling off and gradual decline of environmental degradation. Thus there are both proximate causes of the EKC relationship - changes in economic structure or product mix, changes in technology and changes in input mix - and underlying causes such as environmental regulation, awareness and education. These effects act to counteract or exaggerate the gross impact of economic growth or the scale effect.

Stern reviews the four main types of contributions to the literature: estimation of 'basic' EKCs, studies of the theoretical determinants of the EKC, studies of 
the empirical determinants of the EKC and critiques of EKCs. Stern concludes that there has been progress on understanding the EKC in the last few years and some progress in methods of investigation. Evidence continues to accumulate that the inverted $U$ shape relation only applies to a subset of impacts and that overall impact, perhaps approximately indicated by per capita energy use, rises throughout the relevant income range.

Stern describes advances in our understanding of the determinants of the EKC. It is clear that structural change and technological progress are of importance. Democracy, a variable that is also a correlate of development, is also associated with lower emissions. There is, however, increasing evidence that the EKC is partly determined by trade relations. If this is so, the poorest countries of today will find it more difficult than today's developed countries to reduce environmental impact as income rises. Some studies present more disaggregated evidence that is of interest in evaluating the performance of individual countries and the influence of particular events. Change may occur quite rapidly in crisis periods such as those of the oil price shocks of the 1970s or the CFC negotiations of the 1980s. Some of the empirical relationships that have been uncovered may not be robust, though this is not yet known: the issue of omitted variables bias has not been adequately investigated.

In Chapter 9, Richard England summarizes the many continuing efforts to develop alternatives to gross domestic product. Efforts to measure a nation's aggregate income date back to the seventeenth century when Sir William Petty devised one of the first national income estimates. It is widely recognized, however, that the economic crisis of the Great Depression, the political and military conflict of the Second World War and the emergence of Keynesian macroeconomic theory prompted the creation of modern national income accounting. National income statistics have found a variety of practical uses. For instance, they help to inform the design of government fiscal and monetary policies, influence corporate investment plans and are commonly used to assess economic development strategies in less developed nations. From their inception, however, the national income and product accounts have also been used to make international comparisons of wellbeing and to track changes in a country's level of welfare.

During the past quarter century, national income, GDP and allied accounting concepts have been sharply criticized by a wide array of commentators. Many of those critics have questioned whether national income data adequately measure the level of, or changes in, economic wellbeing. England notes that a typical defence of GDP has been to simply deny that they serve as measures of economic welfare. Yet leading economic historians and macroeconomists readily cite data on real per capita GDP as though they can provide insights into standards of living and economic progress. England goes on to identify the major issues involved in the development of complements to, or substitutes 
for, GDP. These include the need to properly specify the distinction between intermediate and gross final output, the need to account for asset depreciation in a comprehensive manner, the need to divide net final output between consumption and capital accumulation on a reasonable basis, and the need to take account of the welfare implications of various forms of social inequality.

Cutler Cleveland and David Stern review the different methods used to analyse resource scarcity, including their underlying theories, methodologies and principal empirical results. In general terms, an increase in scarcity is defined by a reduction in economic wellbeing due to a decline in the quality, availability or productivity of natural resources and vice versa. A major issue in the literature on the measurement of natural resource scarcity is which of the alternative indicators of scarcity, such as unit costs, prices, rents, elasticities of substitution and energy costs, is superior. Most neoclassical economists argue that, in theory, price is the ideal measure of scarcity. The unit cost indicator is derived from the classical school of economics. Some ecological economists favour a biophysical model of scarcity and derive energy-based indicators. A central issue is under what economic, technological, institutional and environmental conditions each indicator provides clear or ambiguous signals of scarcity.

Cleveland and Stern propose the terms use scarcity and exchange scarcity to distinguish between two broad approaches to measuring scarcity. These terms relate to the classical concepts of use and exchange value. Definitions of use and exchange value have varied among the different economic paradigms. Broadly speaking, use value is the value derived from consumption of a good, while exchange value is the value of goods or money that can be obtained in exchange for the good in an actual or potential market. Use scarcity refers to the ability of natural resources to generate use value and is typically measured in terms of the balance between the productivity and availability of the resource base and the level of technology. Exchange scarcity is commonly measured by price or rent, depending on whether the scarcity of in situ natural resources or of resource commodities is being measured.

Cleveland and Stern argue that a research programme aimed at modelling resource supply that takes into account both physical and economic factors would perhaps be more useful than the simple calculation of scarcity indicators. Rather than just observing the trend in costs or prices and assuming that this will continue into the future, this approach seeks to differentiate between the various causes of change in scarcity. This would give us a better picture of the limits to improvements in the future. Together with information on the possibilities for future technical change and natural processes, such models could be used to produce scenarios about possible future scarcity trends that could inform debate and policy making.

Finally, Costanza et al. review the goals and methods of green national accounting. They argue that a clear understanding of the different goals being 
served by different accounting frameworks is a prerequisite for their effective interpretation and use. They describe the range of goals for green accounting and the corresponding frameworks and methods which are most appropriate for each goal. The goals are divided into three broad categories, measuring economic income, economic welfare and human welfare. Most conventional national accounting measures, such as gross national product and net national product (GNP, NNP), limit themselves to measuring economic income, which is admitted to have no direct relationship to welfare. Despite this admitted lack of connection to welfare, economic income measures are routinely used as welfare surrogates, on the assumption that more income means more welfare. Within this category of income measures one can distinguish marketed, weakly sustainable and strongly sustainable versions, depending on how the depletion of capital and the substitutability between natural and human-made capital is dealt with.

But increases in economic income may not correlate with increases in economic welfare, especially if the income measures do not adequately distinguish 'costs' from 'benefits'. For example, an oil spill can increase GNP because more activity and income are generated, but it does not increase welfare since this activity is a cost to be avoided. The goal of measuring economic welfare requires adjusting income to better reflect which items in the income measures are costs and benefits and subtracting the costs (such as natural capital depletion and pollution), imputing values to missing services (such as household labour) and adjusting for income distribution effects using indices of income distribution. The Index of Sustainable Economic Welfare (ISEW) is one such economic welfare measure.

But economic welfare measured as the production of net benefits may still not correlate with overall human welfare, since many human needs are not related to consumption of economic products or services. The goal of measuring overall human welfare requires directly assessing the degree to which human needs are actually being met, the economic production involved being only one of many possible means to these ends. Costanza et al. further elaborate these distinctions and the specifics of measuring economic income, economic welfare and human welfare to produce a much needed clarification of these increasingly important issues. 
Cutler J. Cleveland, Robert Costanza, and David I. Stern - 9781843761419 Downloaded from PubFactory at 04/26/2023 12:54:28PM 